\title{
THE EFFECTS OF THE RATE OF ADMINISTRATION OF AMINO ACID PREPARATIONS ON URINARY WASTAGE OF AMINO ACID NITROGEN IN MAN
}

\author{
By CHARLEY J. SMYTH, STANLEY LEVEY, AND ANDREW G. LASICHAK \\ (From the Departments of Medicine and Physiological Chemistry of Wayne University College \\ of Medicine, Detroit, and the Wayne County General Hospital and \\ Infirmary, Eloise, Michigan)
}

(Received for publication January 8, 1948)

One of the major objections to the clinical use of mixtures of amino acids derived from hydrolysis of casein is the occurrence of nausea, vomiting, flushing, and headaches. These undesirable symptoms occur more frequently if the rate of administration is rapid. In a previous communication (1) it was shown that the elimination of many of these reactions could be accomplished by reducing the rate of infusion; it was further observed that mixtures of amino acids could be given at exceedingly rapid rates $(100 \mathrm{ml}$. of a 10 per cent mixture per minute or the equivalent of 100 grams of protein could be given intravenously in less than three hours) without causing any discomfort to the patient.

Earlier investigators $(2,3,4)$ found that if amino acid preparations were given intravenously at a slow rate, usually less than 8 per cent of the administered amino acid nitrogen was lost by urinary spillage. Thus, it was desirous to learn whether the advantages gained by the rapid intravenous infusion of the well-tolerated amino acid mixtures might be offset by an increased urinary loss. This study was planned to compare the urinary amino acid nitrogen loss following the intravenous administration of amino acid mixtures at rapid rates with the loss which occurred following the intravenous injection of casein digests at rates approaching maximum tolerance. In addition, studies were designed to obtain comparable control data regarding the amount of amino acid nitrogen lost due to the "washing-out" effect following the injection of equal volumes of physiological saline.

\section{METHODS}

Male patients with no detectable metabolic disorders were used as subjects for this study. All food was withheld after the previous evening meal until the four-hour study period of the following morning was completed. On the morning of the day of the study the patient emptied his bladder and the intravenous injection of the test solution was started; all voided urine was collected for the next four hours with the patient emptying his bladder at the end of the period. The same method for urine sample collection was used with each preparation studied. The interval between each test for a given patient varied from three to five days, thus providing a period for stabilization. By using a urine collection period of only four hours an important practical advantage was gained in that there was only a slight interference with the general hospital routine; the patient lost only one meal (breakfast) and was therefore more cooperative during the entire period of study.

Three amino acid preparations were used: Preparation I 1, 2 consisted of a 10 per cent solution of an enzymatic hydrolysate of casein, Preparation II ${ }^{3}$ was an acid hydrolysate of casein fortified with tryptophane, and Preparation V ${ }^{4}$ was a "VUJN" type of mixture of amino acids prepared by the recombination and fortification of fractions of a casein hydrolysate. All amino acid solutions used were diluted with sterile water to provide a test dose which had a total nitrogen content of approximately 5.4 gms. per $500 \mathrm{ml}$.

The first group of five patients received in successive periods of study all three amino acid preparations and the physiological saline control solution at a constant rate of $500 \mathrm{ml}$. in two hours. The second group of ten patients received the test dose of the three amino acid preparations at different rates of injection: Preparation I was given in one and one-half hours, Preparation II in two hours and Preparation V in one hour. The amino acid preparations in this phase of the study were administered at rates which previous experience had shown approached the maximum tolerated rate in the majority of the patients. A third group of four patients each received Preparation $\mathrm{V}$ administered first at a rate of

\footnotetext{
1 Preparation I (Amigen, 10 per cent solution) was supplied by Mead Johnson and Company, Evansville, Indiana.

2 The numbers designating the preparations are the same which have been used in previous reports from this laboratory.

3 Preparation II (Parenamine 15 per cent) was supplied by Frederick Stearns and Company, Detroit, Michigan.

${ }^{4}$ Preparation V (VUJN-IX) was supplied by Merck and Company, Inc., Rahway, New Jersey.
} 
$500 \mathrm{ml}$. in two hours and subsequently the same amount in 35 minutes.

The amino acid nitrogen content in the urine was estimated by the copper method of Albanese and Irby (5). Free amino acid nitrogen was determined by doing the analysis directly on the urine. Total amino acid nitrogen was determined in the urine samples after hydrolysis which was accomplished by mixing $20 \mathrm{cc}$. of urine with $5 \mathrm{cc}$. of concentrated $\mathrm{HCl}$ and autoclaving at $120^{\circ} \mathrm{C}$. for five hours. The difference between the total and the free amino acid nitrogen was considered to be "bound" amino acid nitrogen.

\section{RESULTS}

The results of the comparison of the urinary losses of amino acid nitrogen as initially observed by infusing all three of the preparations studied at the same rate and also at the same total nitrogen level are summarized in Figure 1. In addition to the amino acid preparations, these patients subsequently received an infusion of physiological saline at the same rate, the amino acid nitrogen lost in the urine is also presented in this same figure. Under the conditions of the experiment, Prepara- tion I caused the largest amount of total amino acid nitrogen to appear in the urine; variations in the amounts of total amino acid nitrogen excreted during the four-hour test period were great, the extremes being 300 and $900 \mathrm{mg}$., with an approximate average of $550 \mathrm{mg}$. The increased loss of total amino acid nitrogen appeared to be due mainly to "bound" amino acid nitrogen, since the loss of free amino acid nitrogen was of the same magnitude as with the other two preparations tested. The amount of "bound" amino acid nitrogen excreted after the infusion of Preparation I was approximately equal to the total amino acid nitrogen excretion with the other two preparations. The amount of "bound" nitrogen excreted following the administration of either Preparation II or $\mathrm{V}$ was of the same general magnitude as that found in the urine after the saline infusion. Following the administration of Preparation II an average of about $400 \mathrm{mg}$. of total amino acid nitrogen appeared in the urine during the four-hour period; the amounts of free and bound amino acid nitrogen

FOUR HOUR URINARY AMINO ACID NITROGEN EXCRETION FOLLOWING $5.4 \mathrm{GM}$. NITROGEN INFUSION*

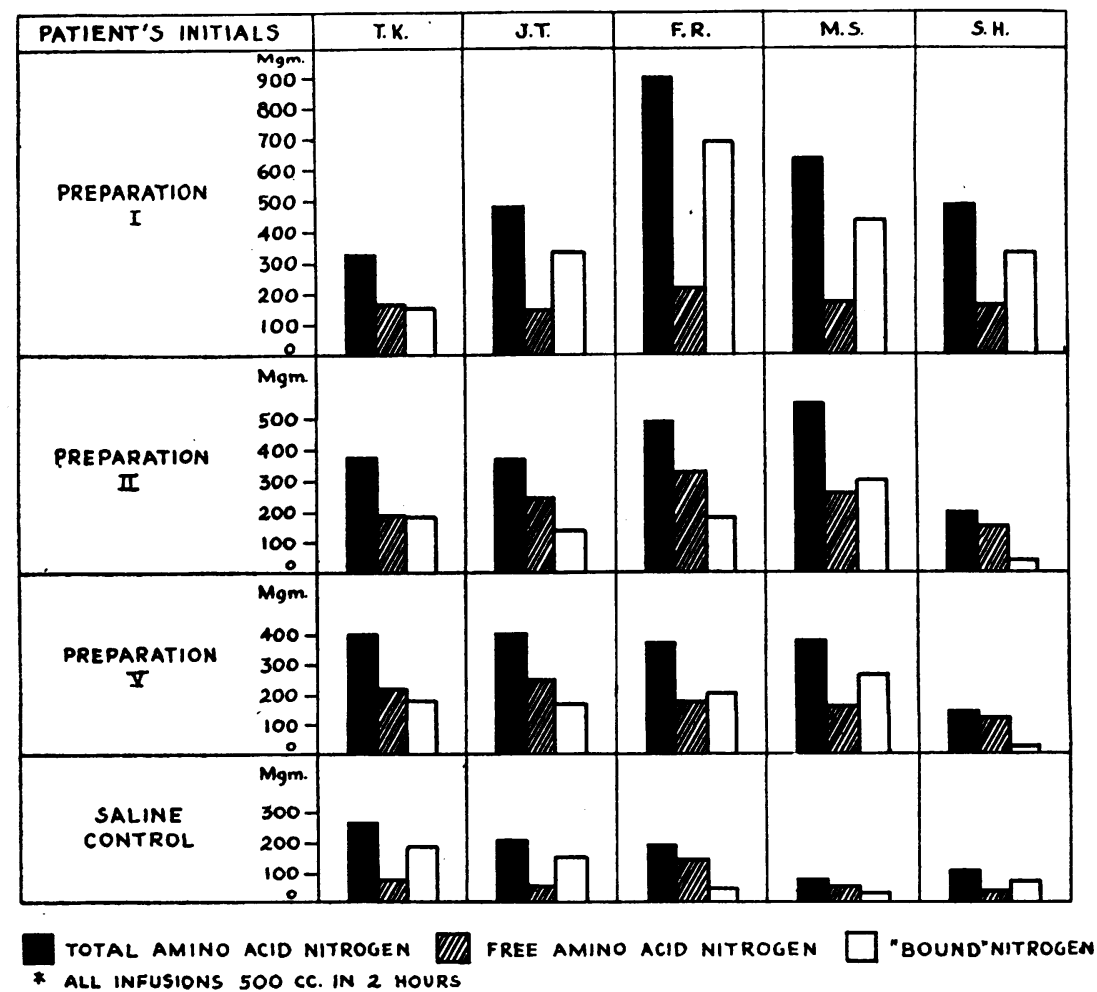

FIG. 1 
FOUR HOUR URINARY AMINO ACID NITROGEN EXCRETION

FOLLOWING $5.4 \mathrm{GM}$. NITROGEN INFUSION *

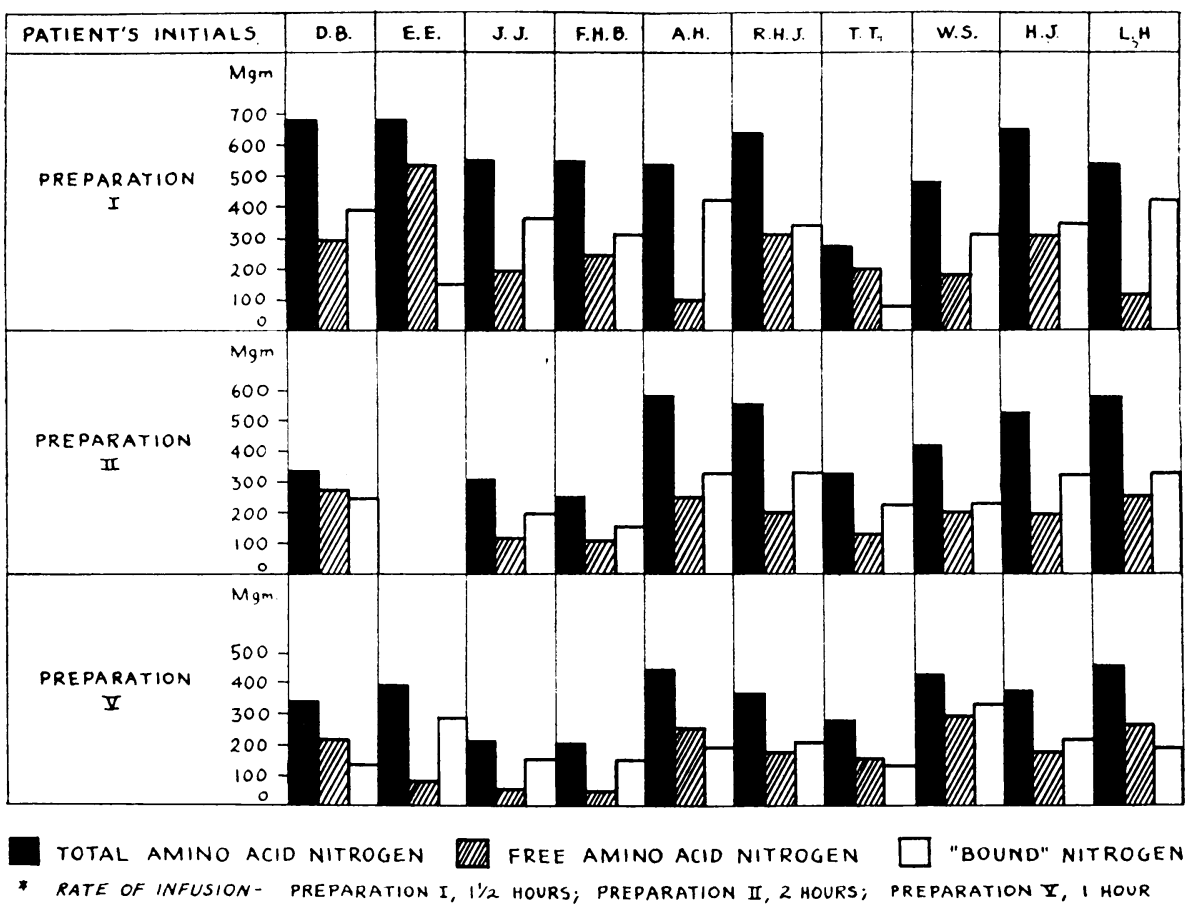

FIG. 2

were almost equal in the five patients studied. The amino acid excretion pattern following the administration of Preparation $\mathrm{V}$ was in general similar to that of Preparation II, approximately $400 \mathrm{mg}$. of amino acid nitrogen being lost.

If the amount of total amino acid nitrogen excreted following the saline infusion were subtracted from the total amino acid wastage, which followed the administration of Preparation II or $\mathrm{V}$, there would be little nitrogen lost during the four-hour test period, with subject M. S. being an exception. This becomes evident if a vertical comparison for any one subject is made of the data in Figure 1. If a comparison is made of the free amino acid nitrogen lost following the administration of all three preparations, the small amounts and the relative constancy of the free amino acid excretion are striking.

Since both the amount of total amino acid nitrogen administered to subjects and the amount of total amino acid nitrogen excreted due to the infusion were known, it was possible to determine the per cent of administered total amino acid nitrogen wasted due to urinary spillage. This is summarized in Table I. The per cent of administered total amino acid nitrogen of Preparation I lost ranged between 1.6 and 19.7. The amount of Preparations II and V lost under similar conditions was less variable and usually ranged about three to five per cent.

A study of the urinary wastage of amino acid nitrogen after intravenous administration of the three preparations investigated given at different rates is presented in Figure 2. It should be noted that Preparation I was administered in a one and one-half hour period, while Preparation II was administered in a two-hour period, and Preparation $\mathrm{V}$ was injected in the short period of only one hour. It is of interest that usually less total amino acid nitrogen was lost in the urine after the administration of Preparation $\mathrm{V}$ than with other preparations tested, although the speed of its administration was greatest. In only one case ( $T$. T.) was more amino acid nitrogen lost after the administration of Preparation $\mathrm{V}$ than with either of the other products.

Since it was previously shown that an amino acid mixture (Preparation V) could be tolerated 
well at exceedingly rapid rates of administration (1), the effect of rapid infusions of this preparation on the urinary wastage of amino acid nitrogen was investigated more intensively (Figure 3). Four subjects received Preparation V intravenously in a two-hour period and the urinary wastage of amino acid nitrogen was determined. Subsequently, after a three- to five-day period, these same four subjects received $500 \mathrm{ml}$. of this same amino acid mixture in a 35-minute infusion. In three of the four patients studied, there was less amino acid nitrogen spilled in the urine following the rapid rate than at the slower rate of infusion.

\section{DISCUSSION}

No direct comparison of the excretion values presented in this study with those available in the literature is possible because the periods of urine collection are different. However, in general, the amounts of amino acid nitrogen lost in the fourhour period are comparable to the values reported in the literature for periods from 12 to 24 hours. It would appear that the major wastage occurs during the first few hours following the intravenous administration.

By determining the amount of amino acid nitrogen in the urine following the administration of physiological saline in a given patient, it was possible to estimate the amino acid wastage in that pa- tient due to the "washing-out" effect produced by fluid containing no nitrogen. In considering the data present in Table I, it should be noted that the amount of amino acid nitrogen lost in the urine was calculated as the difference between the amount lost in the four hours following the beginning of the amino acid infusion and the amount lost in a similar period following a saline injection. These values represent, therefore, the amino acid wastage due only to the supplementary alimentation.

TABLE I

The per cent of administered total amino acid nitrogen excretion in a four-hour period after giving the various preparations intravenously

The amino acid nitrogen losses following the physiological saline infusion have already been subtracted from the values in the table.

\begin{tabular}{l|c|c|r|r|r}
\hline \hline Patients' initials & T. K. & J. T. & F. R. & M. S. & S. H. \\
\hline Preparation I & 1.6 & 7.6 & 19.7 & 14.9 & 10.4 \\
Preparation II & 3.4 & 5.1 & 9.4 & 13.7 & 1.9 \\
Preparation V & 3.5 & 4.8 & 4.3 & 7.5 & 0.9 \\
\hline
\end{tabular}

The excretion of total amino acid nitrogen after the administration of Preparation I was greater than with the other preparations tested. From the data in Figure 1 it is noted that there were large increases in "bound" nitrogen; furthermore, this increased loss of "bound" nitrogen is sufficient to account for the large loss of total amino

\section{FOUR HOUR URINARY AMINO ACID NITRÖGEN EXCRETION FOLLOWING $5.4 \mathrm{GM}$. NITROGEN INFUSION PREPARATION $\boldsymbol{Z}$}

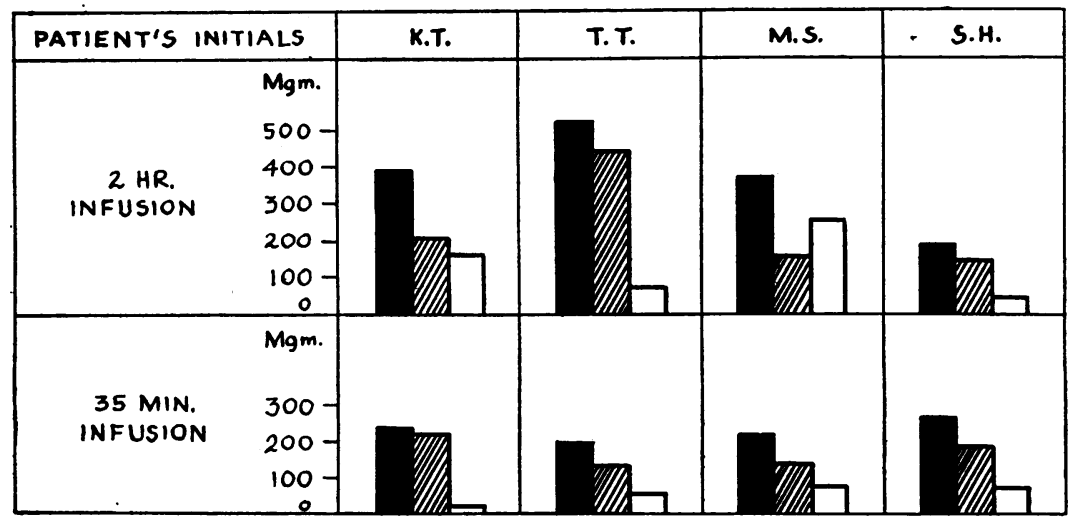

TOTAL AMINO ACID NITROGEN FREE AMINO ACID NITROGEN "BOUND" NITROGEN 
acid nitrogen. Christensen and co-workers (6) have reported that human subjects have a limited ability to retain peptides, for after the administration of an enzymatic hydrolysate of casein (Amigen) the peptides were rapidly excreted by the kidney without a measurable quantity being present in the blood stream. Christensen also concluded that these observations indicate that the tissue utilization of peptide nitrogen is definitely limited. Increased urinary loss of "bound" amino acid nitrogen has also been found to occur in dogs after the intravenous administration of Amigen by Cox and Mueller (7). Recently, Christensen and associates (8) have reported observations concerning the urinary loss of "bound" amino acid nitrogen following the intravenous administration of two different peptide-containing protein hydrolysates and stated that the "bound" amino acid nitrogen in a fibrin hydrolysate was better utilized than that present in an enzymatic hydrolysate of casein. These workers proposed a new concept, suggesting that large urinary losses of "bound" amino acid nitrogen following intravenous administration of a partial hydrolysate of protein may offer the possibility of serious losses, either of a qualitative or quantitative nature, of the injected amino acids.

Preparation V had the marked clinical advantage in that it could be given at exceedingly rapid rates without producing ill effects. Yet, in spite of this rapid rate of infusion, approximately $15 \mathrm{ml}$. per minute, there was little or no increase in the wastage of amino acid nitrogen as measured by an increase in urinary amino acid nitrogen. Silber, Seeler, and Howe (4), working with dogs, have shown that doubling the rate of administration of a preparation similar to Preparation V, from 6 to $12 \mathrm{mg}$. of nitrogen per $\mathrm{Kg}$. per minute did not increase the rate of urinary loss of amino acid nitrogen. The work presented here, using human subjects and a rapid administration of amino acids (Preparation V), is in agreement with their report. It is rather striking that so little free amino acid nitrogen is lost after the intravenous administration of any of the preparations tested as compared to the amount of amino acid nitrogen administered. This is true, regardless of the speed of infusion, providing the material is well tolerated. From the data presented in the four-hour test period, it appears that the human organism holds tenaciously to amino acid nitrogen given intravenously.

Individual variation of patients was rather great in regard to the urinary excretion of amino acid nitrogen. This is illustrated in Table I where patient M. S. had high urinary losses of amino acid nitrogen regardless of the preparation given. Inspection of the total amino acid nitrogen excretions given in Figure 2 further stresses this point.

One of the major purposes of this work was to determine whether with rapid rates there was increased spillage of the amino acid preparation into the urine. From the data presented, it may be concluded that there is little if any increased amino acid wastage due to the rapid rate of administration of the VUJN type of mixture of amino acids.

\section{SUM MARY}

A comparison was made in 15 human subjects of the urinary loss of amino acid nitrogen in a four-hour period following the administration of three different amino acid preparations, each containing $5.4 \mathrm{gm}$. of nitrogen. In addition, in five of these patients the amino acid nitrogen content of the urine was determined for the same period after an infusion of physiological saline. The injections of the protein hydrolysates were given at rates which previous experience had shown to approach the maximum tolerated rate in the majority of the patients.

The greatest urinary wastage of amino acid nitrogen occurred with the amino acid solutions prepared by the enzymatic hydrolysis of casein, a preparation containing large amounts of peptide nitrogen. The increased loss of total amino acid nitrogen which followed the use of this digest appeared to be due mainly to "bound" amino acid nitrogen, since the loss of free amino acid nitrogen was of the same magnitude as with the other preparations tested.

The per cent of the total administered amino acid nitrogen lost in the urine in a four-hour period following the enzymic hydrolysate of casein ranged between 1.6 and 19.7 per cent. Under similar conditions, usually 3 to 5 per cent of the total amino acid nitrogen was found in the urine after the administration of either an acid hydrolysate of casein or a mixture of amino acids. In contrast, 
there was little free amino acid nitrogen lost after the administration of any of the preparations studied regardless of the speed of infusion. Mixtures of amino acids, if well tolerated, can be given at exceedingly rapid rates without causing increased spillage into the urine.

\section{BIBLIOGRAPHY}

1. Smyth, C. J., Lasichak, A. G., and Levey, S., The effect of the rate of administration of amino acid preparations and blood amino acid nitrogen level on the production of nausea and vomiting. J. Lab. \& Clin. Med., 1947, 32, 889.

2. Landesman, R., and Weinstein, V. A., Intravenous use of amino acids for nutritional purposes in surgical patient. Surg. Gynec. \& Obst., 1942, 75, 300.

3. Altshuler, S. S., Hensel, H. M., Hecht, P., and Pursley, R., Maintenance of nitrogen equilibrium by intravenous administration of amino acids; clinical studies. Arch. Int. Med., 1942, 70, 749.
4. Silber, R. H., Seeler, A. C., and Howe, E. E., Urinary excretion of $\alpha$-amino nitrogen following intravenous administration of amino acid mixtures. J. Biol. Chem., 1946, 164, 639.

5. Albanese, A. A., and Irby, V., Determination of amino nitrogen of blood filtrates by copper method. J. Lab. \& Clin. Med., 1945, 30, 718.

6. Christensen, H. N., Lynch, E. L., and Powers, J. H., The conjugated, non-protein amino acids of plasma. III. Peptidemia and hyperpeptiduria as a result of the intravenous administration of partially hydrolyzed casein (Amigen). J. Biol. Chem., 1946, 166, 649.

7. Cox, W. M., Jr., and Mueller, A. J., The relative efficiency of different forms of intravenously administered nitrogen on the nitrogen balance and amino acid excretion. J. Nutrition, 1946, 31, 581.

8. Christensen, H. N., Lynch, E. L., Decker, D. G., and Powers, J. H., The conjugated non-protein amino acids of plasma. IV. A difference in the utilization of the peptides of hydrolysates of fibrin and casein. J. Clin. Invest., 1947, 26, 849. 